\title{
Degradação ambiental agropecuária e seus determinantes em Minas Gerais
}

RESUMO

Samuel Alex Coelho Campos ${ }^{1}$

Marília Fernandes Maciel Gomes ${ }^{2}$

Alexandre Bragança Coelho ${ }^{3}$

O presente estudo determinou a importância da produção e das práticas adotadas pelos estabelecimentos agropecuários sobre a degradação ambiental nos municípios mineiros, em 2006. Para tal foi utilizado o Índice Geral de Degradação (IGD) e a regressão quantílica. As estimativas demonstram a importância das práticas agropecuárias, atividades agropecuárias e mecanização sobre a degradação. Pela análise, destacam-se: (i) o valor ótimo de utilização da rotação de culturas, do plantio em nível e da renovação de pastagens para o controle da degradação; (ii) a importância da reserva legal para o controle da degradação proveniente da agropecuária; e (iii) a importância da intensidade da produção agropecuária para a degradação. Ações de maior eficácia e eficiência para redução da degradação agropecuária podem ser propostas por meio dessas considerações.

Palavras Chave: Degradação, Minas Gerais, Agropecuária.

JEL: D2, Q5, R1.

\section{Agricultural Environmental Degradation and its Determinants in Minas Gerais}

\section{ABSTRACT}

This study sought to determine the importance of production and farm practices adopted by agricultural establishments on the level of environmental degradation on Minas Gerais cities in 2006. The General Index of Degradation (IGD) and quantile regression were used. Results show the importance of agricultural practices, mechanization and activities on the level of degradation. Most important results are: (i) the optimum use of crop rotation, planting level and renovate pastures to control the degradation as a strategy to control the degradation; (ii) the importance of the legal reserve to control the agricultural degradation; (iii) the importance of the agricultural production intensity to degradation. Actions more effective and efficient to reduce the agricultural degradation can be proposed by these considerations.

Key Words: Degradation, Minas Gerais, Agricultural.

JEL: D2, Q5, R1.

\footnotetext{
1 Professor Adjunto Universidade Federal Fluminense / Instituto de Ciências da Sociedade e Desenvolvimento Regional. Graduação em Gestão do Agronegócio - Universidade Federal de Viçosa; Mestre em Economia Aplicada - Universidade Federal de Viçosa; Doutor em Economia Aplicada. Departamento de Economia, Administração e Sociologia, Escola Superior de Agricultura "Luiz de Queiroz"/ Universidade de São Paulo.

2 Professora Associada IV da Universidade Federal de Viçosa. Graduada em Matemática pela Universidade Federal de Viçosa, mestrado em Economia Rural pela Universidade Federal de Viçosa e Doutorado em Economia Aplicada pela Universidade Federal de Viçosa.

3 Professor Associado da Universidade Federal de Viçosa. Graduação em Ciências Econômicas, Universidade de São Paulo; Mestre em Economia - Universidade de São Paulo. Doutor em Economia Aplicada pela Universidade Federal de Viçosa.
} 
O agronegócio mineiro foi responsável por $13,86 \%$ do PIB do agronegócio brasileiro em 2016 e contribuiu com 210,376 bilhões para o PIB mineiro (BARROS et al., 2017). A esse setor de relevância para a economia mineira é, geralmente, atribuída a degradação dos recursos naturais. Esse aspecto tem despertado a atenção da sociedade, de forma que os impactos da produção agropecuária têm recebido críticas constantes quanto à forma de produção não sustentável, por utilizar pesticidas que contaminam o meio ambiente, pelo desmatamento, erosão e salinização do solo, eutroficação, queimadas, desertificação e redução da taxa de infiltração, da quantidade e da qualidade da água disponível (RODRIGUES, 2005; SINGH, 2000; SOARES; FREITAS; COUTINHO, 2005; EL KHASLILI, 2007; ENGSTRÖM et al., 2007; CUNHAS et al., 2008).

Algumas atividades produtivas destacam-se em Minas Gerais quanto ao potencial de degradação ambiental, dada suas especificidades produtivas e extensão da área ocupada, como a bovinocultura de leite, a suinocultura, a avicultura, a bataticultura, o cultivo de tomates, de café e de milho, e nessas atividades o Estado tem-se sobressaído entre os cinco maiores produtores (SIBRA-IBGE, 2012).

A suinocultura, segundo Mallmann et al. (2009), apresenta grande potencial de poluição, tanto do ar como das águas; a produção avícola, impacta o meio ambiente pela emissão de gases, odores, poeiras e lançamento de efluentes em corpos de água (PALHASRES, 2007); a bataticultura, pelo preparo excessivo do solo para o plantio, lixiviando o solo e reduzindo a flora microbiana (FERNANDES, CUNHA, SILVA; 2005); o cultivo de tomates, que devido à sua perecibilidade natural, assim como a bataticultura, exige grande quantidade de agrotóxicos, que muitas vezes são utilizados de modo inadequado e excessivo, contaminando o meio ambiente e os consumidores; a produção de leite, pelo desmatamento para a formação de pastagens e consequente erosão e lixiviação, emissões de nitrogênio via urina e dejetos e emissões de $\mathrm{CO}_{2}$ (DI; CAMERON, 2000; 2008); a cafeicultura, pela retirada das matas para o plantio dos cafezais, redução da biodiversidade e aplicação de fertilizantes (as plantas retiram nutrientes do solo que necessitam ser repostos para manter a produtividade), que podem ser lixiviados e contaminar os corpos de água (WATSON, 2005); e a produção do milho que apresenta potencial de degradação pela compactação do solo pelo trânsito intenso de máquinas, no sistema convencional (VIANA et al., 2006).

Em adição ao impacto da produção agropecuária sobre a qualidade ambiental $^{4}$, as características geográficas, somadas às tecnologias utilizadas e a intensidade produtiva contribuem para a degradação dos recursos naturais. $O$ padrão da produção agropecuária é importante na compreensão da degradação, na medida em que a utilização intensiva de máquinas, agrotóxicos e fertilizantes eleva a pressão sobre o meio ambiente e acelera a degradação

${ }^{4}$ Qualidade ambiental é a capacidade que um determinado ecossistema apresenta em manter e sustentar os seres vivos nele existentes (CARVALHO et al, 2008), embora se esteja englobando apenas a vegetação nativa, qualidade da água superficial e perdas de solo. 
(MAROUELLI, 2003; VIANA et al., 2006). Assim, a maior utilização de equipamentos, fertilizantes e o plantio em áreas de grande declividade ou margens de rios, podem resultar em degradação. Desta forma, as condições geográficas acidentadas, com clima seco e vegetação agreste caracterizam regiões com alta vulnerabilidade ambiental, como, para o estado mineiro, as macrorregiões Sul, Noroeste, Norte e Triângulo Mineiro podem ser consideradas de alta vulnerabilidade.

Por outro lado, segundo Carvalho et al. (2008), as práticas de conservação do solo como o plantio em nível, plantio direto, conservação de matas, manutenção das matas próximas aos rios, utilização de práticas adequadas de plantio e sistema produtivo adequadamente dimensionado podem ser utilizadas para a prevenção e controle da degradação.

No Brasil, de forma geral, os estudos econômicos que tratam da degradação ambiental, proveniente da agropecuária estimaram índices na tentativa de quantificar a degradação proveniente da agropecuária, como Lemos (2001), para o Nordeste brasileiro; Silva e Ribeiro (2004), para o estado do Acre; Fernandes, Cunha e Silva (2005), para o estado de Minas Gerais; e Cunha et al. (2008) para a região do Cerrado.

Entretanto, apesar da diversidade de fatores relacionados à degradação ambiental, pouco tem sido feito quanto à consideração dos fatores relacionados à produção agropecuária (tecnologia de produção, práticas e atividades agropecuárias e intensidade da produção agropecuária) sobre a degradação. Surge então a indagação: Qual a contribuição da intensidade da produção agropecuária, da produção agropecuária e das práticas agropecuárias adotadas pelos estabelecimentos agropecuários sobre a degradação ambiental no estado de Minas Gerais, em 2006? Especificamente, pretende-se determinar o nível de degradação ambiental da atividade agropecuária; estabelecer a importância da intensidade agropecuária e da produção de batatas, tomates, suínos, milho, café, aves e da pecuária de corte e de leite sobre a degradação ambiental; bem como determinar a importância das práticas agropecuárias adotadas pelos estabelecimentos sobre a degradação.

Este artigo está dividido em quatro seções, além desta. Na segunda seção descreve-se a metodologia utilizada para a estimação e análise da degradação ambiental dos municípios mineiros, bem como os dados utilizados e a fonte dos mesmos. Na terceira seção são apresentados e discutidos os resultados. Por fim, na última seção são feitas as conclusões finais, apontadas as limitações do estudo e as sugestões para pesquisas futuras.

\section{Metodologia}

Inicialmente, foi utilizada a análise fatorial como estratégia de estimação do índice de degradação ambiental da agropecuária para o estado de Minas Gerais e, posteriormente, uma regressão quantílica foi estimada com o intuito de determinar a contribuição dos fatores relacionados com a produção, tratados anteriormente, sobre a degradação, permitindo discriminar a relação dessas variáveis com a maior ou menor degradação ambiental.

\subsection{Análise fatorial}

Revista de Estudos Sociais | Ano 2017, N. 38, V. 19, Pag. 52 
A análise fatorial descreve a variabilidade original do vetor aleatório $X$, em termos de um número menor $(\mathrm{m})$ de variáveis aleatórias que sumarizem as informações das variáveis originais. Determinando um número "j" de fatores a serem extraídos, os escores fatoriais " $\mathrm{f}_{j}$ " podem ser calculados pela combinação linear das variáveis observáveis xi:

$$
f_{j}=d_{j 1} x_{1}+d_{j 2} x_{2}+\ldots+\text { djix }_{i}
$$

em que $d_{m i}$ são os coeficientes dos escores fatoriais e $x_{i}$ as variáveis originais observáveis. As variáveis observáveis $\left(x_{1}, x_{2}, \ldots, x_{i}\right)$ possuem média zero e desvio padrão igual a um.

\section{2. Índice de degradação ambiental}

Para estimar a degradação ambiental dos municípios mineiros foi usado o índice de degradação ambiental proposto por Lemos (2001), utilizado por Silva e Ribeiro (2004) e Fernandes, Cunha e Silva (2005) e, posteriormente modificado por Cunha et al. (2008).

Para o cálculo do índice, os escores fatoriais foram estimados por meio da análise fatorial. Mediante tais escores, o Índice Geral de Degradação (IGD) foi calculado:

$$
I G D_{i}=\sum_{j=1}^{p} \frac{\lambda_{j}}{\sum \lambda_{j}} f_{j i}^{*}
$$

em que $I G D_{i}$ é o índice para i-ésima microrregião; $\lambda_{\mathrm{j}}$ é a j-ésima raiz característica; $\mathrm{p}$ é o número de fatores extraídos na análise; $f_{j i}^{*}$ é o j-ésimo escore fatorial da i-ésima microrregião; e $\sum \lambda_{j}$ é o somatório das raízes características referentes aos $\mathrm{p}$ fatores extraídos.

Para que todos os escores fatoriais $\left(\mathrm{f}_{\mathrm{ji}}\right)$ estejam no intervalo de 0 a 1 , todos eles são colocados no primeiro quadrante, antes da construção do IGD, adotando o procedimento matemático também empregado por Lemos (2001), Fernandes, Cunha e Silva (2005), e Cunha et al. (2008):

$$
f_{j i}^{*}=\frac{f_{j i}-f_{j}^{\min }}{f_{j}^{\max }-f_{j}^{\min }}
$$

em que $f_{j}$ min é o menor escore observado para $0 j$ - ésimo fator, e $f_{j}$ max é 0 maior escore observado para o j - ésimo fator.

Os escores são trabalhados entre o intervalo 0 a 1 com o intuito de facilitar a interpretação e evitar valores para o IGD negativos. Valores para o IGD próximo a zero referem-se a microrregiões com baixa degradação e microrregiões com valores do IGD iguais ou próximos à unidade retratam regiões com elevada degradação

\subsection{Regressão quantílica}


Considerando a existência de uma relação entre o grupo de variáveis exógenas e a degradação ambiental, foi utilizada a regressão quantílica para estimar a magnitude desse relacionamento. Os modelos comumente utilizados são o modelo Tobit ou a regressão linear clássica que sumarizam o relacionamento entre a variável dependente e as variáveis explicativas pela média, permitindo apenas uma visão parcial da relação entre essas variáveis, uma vez que as relações entre as variáveis explicativas sobre as caldas inferiores e superiores da distribuição da variável dependente são desconsideradas. Uma representação completa é obtida por meio da regressão quantílica, introduzida por Koenker e Bassett (1978), que permite distinguir diferenças de importância e de relação entre as variáveis sobre a mediana e sobre os quantis altos e baixos da variável dependente (HASO; NAIMAN, 2007; CAMERON; TRIVEDI, 2009).

A regressão quantílica estimada permitiu identificar as relações entre as diversas atividades agropecuárias, intensidade do sistema produtivo e adoção de práticas de conservação sobre o IGD nos diversos pontos da distribuição condicional da variável dependente. $\mathrm{O}$ modelo linear pode ser representado por:

$y_{i}^{*}=x_{i}^{\prime} \beta+\varepsilon_{i}$

ou,

$Q_{\theta}\left(Y_{i}: X_{i}\right)=X_{i}^{\prime} \beta_{\theta} \theta \in(0,1)$

em que $Q_{\theta}\left(Y_{i}: X_{i}\right)$ representa o $\theta$ quantil do IGD condicional, dado o vetor de regressores. A regressão quantílica, para o $\theta$-ésimo quantil, $0<\theta<1$, segundo Koenker e Bassett (1978), é definida como qualquer solução para a minimização do problema:

$$
\min _{\beta \in R} n^{-1}\left[\sum_{i \in\left\{i: y_{i} \geq x_{i} \beta\right\}} \theta\left|y_{i}-x_{i} \beta\right|+\sum_{i \in\left\{i: y_{i}<x_{i} \beta\right\}}(1-\theta)\left|y_{i}-x_{i} \beta\right|\right]
$$

$\mathrm{Na}$ interpretação dos coeficientes da regressão quantílica devem ser utilizadas as derivadas parciais do quantil condicional para cada regressor específico, ou seja, a mudança marginal no $\theta$-ésimo quantil condicional. A mudança marginal é calculada da forma usual (HASO; NAIMAN, 2007; CAMERON; TRIVEDI, 2009):

$$
\frac{\partial Q_{q}(y \mid x)}{\partial x_{i}}=\beta_{q j}
$$

Tal procedimento possui vários benefícios quando comparados às regressões lineares "convencionais", tais como parâmetros robustos a outliers e à suposição da distribuição dos dados e caracterização mais rica dos dados (CAMERON; TRIVEDI, 2009). 
A partir das estimativas da variância e covariância, a hipótese de igualdade entre pares de coeficientes $\hat{\beta}_{j}^{(p)}$ e $\hat{\beta}_{j}^{(q)}$, entre diferentes quantis $\mathrm{p} \mathrm{e} \mathrm{q}$, foi testada, usando a estatística de Wald (HASO; NAIMAN, 2007):

$$
\text { Estatística }- \text { Wald }=\frac{\left(\hat{\beta_{j}^{(p)}}-\hat{\beta_{j}^{(q)}}\right)^{2}}{\hat{\sigma_{j}^{(p)}-\beta_{j}^{(q)}}}
$$

Sobre a hipótese nula, a estatística de Wald segue distribuição $x^{2}$, com g graus de liberdade, em que $g$ é o número de hipóteses testadas conjuntamente, ou com distribuição $\mathrm{F}$, sendo $F=\frac{1}{g} \mathrm{~W}$, com $\mathrm{g}$ graus de liberdade no numerador e d graus de liberdade no denominador (CAMERON; TRIVEDI, 2005).

\subsection{Variáveis e tratamento dos dados}

Os dados utilizados foram obtidos do Censo Agropecuário do ano de 2006, dado mais recente disponível, para todos os municípios mineiros ${ }^{5}$. O Censo Agropecuário tem como período de referência o ano de 2006 (1\% de janeiro a 31 de dezembro) e como data de referência para o dia 31 de dezembro de 2006 (compreendendo o ano civil) para os valores monetários.

\subsubsection{Análise fatorial}

A análise fatorial foi executada para a obtenção dos escores fatoriais utilizados no cálculo do IGD. As variáveis utilizadas (Tabela 1) foram descritas em relação à área total dos estabelecimentos, em hectares (AE), ou ao número total de estabelecimentos (NE) como forma de evitar que a magnitude das variáveis influencie os escores fatoriais.

Tabela 1. Variáveis utilizadas na análise fatorial

\begin{tabular}{ll}
\hline Variável & Descrição \\
\hline X1 & Estabelecimentos que adotam práticas de controle de pragas e \\
X2 & doenças/NE. \\
Número de estabelecimentos que utilizaram adubos e corretivos/NE. \\
X3 & Áreas queimadas dos estabelecimentos agropecuários, em hectares \\
& (ha)/AE. \\
X4 Áreas com pastagens degradadas nos estabelecimentos \\
\\
A5 agropecuários, em ha/AE. \\
Áreas degradadas (salinizadas, erodidas, desertificadas), em ha/AE. \\
X6 Número de estabelecimentos que não praticam agricultura orgânica/ \\
NE.
\end{tabular}

5 Os municípios de Raposos e Santa Cruz de Minas foram retirados da amostra, visto que o Censo Agropecuário identificou com o caractere " $X$ " os dados desses municípios por terem menos de 3 (três) informantes. O número de municípios totalizou então 851. 
X7 Número de estabelecimentos agropecuários que aplicam adubos às pastagens/NE.

X8 Número de estabelecimentos que utilizam agrotóxicos/NE.

X9 Número de estabelecimentos agropecuários que reaproveitam, depositam no lixo comum, queimam ou abandonam as embalagens de agrotóxicos no campo/NE.

X10 Valor das despesas agropecuárias com adubos, em mil Reais $(\mathrm{R} \$) / \mathrm{NE}$.

X11 Valor das despesas agropecuárias com corretivos do solo, em mil $\mathrm{R} \$ / \mathrm{NE}$.

X12 Valor das despesas agropecuárias com agrotóxicos, em mil $\mathrm{R} \$ / \mathrm{NE}$.

X13 Valor das despesas agropecuárias com medicamentos veterinários, em mil R\$/NE.

X14 Valor das despesas agropecuárias com combustíveis (Álcool, gasolina, carvão vegetal, graxa, lenha, óleo lubrificante), em mil $\mathrm{R} \$ / \mathrm{NE}$.

X15 Número de estabelecimentos pecuários sem tratamento de esterco dos animais/NE.

X16 Número dos estabelecimentos agropecuários com nascentes, rios, riachos ou lagos não protegidos por matas/NE com recursos hídricos.

Fonte: Elaboração própria

\subsubsection{Regressão quantílica}

Para a estimação da regressão quantílica foram utilizadas as variáveis apresentadas e descritas na Tabela 2.

Tabela 2. Variáveis utilizadas na regressão quantílica

\begin{tabular}{|c|c|}
\hline Variável & Descrição \\
\hline IDG & $\begin{array}{l}\text { Índice geral de degradação ambiental dos municípios } \\
\text { mineiros (variável dependente). }\end{array}$ \\
\hline $\begin{array}{l}\text { Plantio em } \\
\text { nível }\end{array}$ & $\begin{array}{l}\text { Área total dos estabelecimentos agrícolas que plantam em } \\
\text { nível, em ha /AE }\end{array}$ \\
\hline Terraços & $\begin{array}{l}\text { Área total dos estabelecimentos agrícolas que utilizam } \\
\text { terraços, em ha / } \mathrm{AE} \text {. }\end{array}$ \\
\hline Rotação & $\begin{array}{l}\text { Área total dos estabelecimentos cultivadas em sistema de } \\
\text { rotação de culturas, em ha / AE. }\end{array}$ \\
\hline Renovação & $\begin{array}{l}\text { Área total dos estabelecimentos utilizada com lavouras para } \\
\text { reforma e, ou renovação e, ou recuperação de pastagens, } \\
\text { em ha/AE. }\end{array}$ \\
\hline Pousio & $\begin{array}{l}\text { Área total dos estabelecimentos utilizada em pousio ou } \\
\text { descanso do solo, em ha/AE. }\end{array}$ \\
\hline Proteção & $\begin{array}{l}\text { Área total dos estabelecimentos destinada à proteção e, ou } \\
\text { conservação de encostas, em ha/AE. }\end{array}$ \\
\hline Matas & $\begin{array}{l}\text { Área dos estabelecimentos agrícolas com matas e, ou } \\
\text { florestas naturais destinadas à preservação permanente ou } \\
\text { reserva legal, em ha/AE. }\end{array}$ \\
\hline Matas2 & $\begin{array}{l}\text { Área dos estabelecimentos agrícolas com matas e, ou } \\
\text { florestas naturais (exclusive área de preservação permanente } \\
\text { e em sistemas agroflorestais), em ha/AE. }\end{array}$ \\
\hline
\end{tabular}

Revista de Estudos Sociais | Ano 2017, N. 38, V. 19, Pag. 56 


\begin{tabular}{ll}
\hline Variável & Descrição \\
\hline Tomates & Área colhida com tomate rasteiro (industrial), em ha/AE. \\
Batatas & Área colhida com batatas, em ha/AE. \\
Café & Área colhida com café, em ha/AE. \\
Milho & Área colhida com milho, em ha/AE. \\
Pastagens & Área com pastagens naturais e plantadas, em ha/AE. \\
Leite & Número de cabeças de bovinos nos estabelecimentos com \\
& mais de 50 cabeças e com a produção láctea como principal \\
Suínos & atividade agropecuária /NE \\
Tratores & Número de suínos, em cabeças/NE. \\
Implementos de tratores, em unidades/NE. & Número de máquinas e implementos agrícolas existentes nos \\
& estabelecimentos agropecuários (arados, grades e, ou \\
& enxadas rotativas, roçadeiras, semeadeiras e, ou \\
& plantadeiras, colheitadeiras, pulverizadores e, ou \\
& atomizadores, adubadeiras e, ou distribuidoras de calcário e \\
& ceifadeiras), em unidades/NE.
\end{tabular}

Fonte: Elaboração própria

3. Resultados e discussão

3.1. Análise fatorial e índice de degradação municipal

Por meio da análise fatorial foram obtidos os fatores e autovalores. Os seis primeiros fatores foram selecionados, uma vez que seus respectivos autovalores são maiores que 1 (Tabela 3 ). Autovalores maiores que 1 captam pelo menos a variância da variável original. O percentual da variância total explicada por cada fator esta representado por "\% Variância" (Tabela 3). Assim sendo, o primeiro fator explicou $18,09 \%$ da variabilidade total dos dados e, no acumulado, os seis fatores explicaram $61,29 \%$ da variância total.

Tabela 3. Fatores extraídos através da análise fatorial

\begin{tabular}{cccc}
\hline Fatores & Autovalor & \% Variancia & \% Acumulado \\
\hline 1 & 2,8950 & 18,09 & 18,09 \\
2 & 1,7152 & 10,72 & 28,81 \\
3 & 1,5551 & 9,72 & 38,53 \\
4 & 1,4226 & 8,89 & 47,42 \\
5 & 1,1789 & 7,37 & 54,79 \\
6 & 1,0397 & 6,50 & 61,29 \\
\hline
\end{tabular}

Fonte: Elaboração própria

A análise fatorial pressupõe-se que as variáveis são correlacionadas entre si. Essa correlação foi avaliada pelo teste de esfericidade de Bartlett. $O$ valor estimado, com distribuição $X^{2}$ com 120 graus de liberdade, foi de $X^{2}=$ $2.879,08$, indicando que a correlação entre as variáveis é significativa em nível de significância de $1 \%$, o que permite rejeitar a hipótese nula (Ho: A matriz de correlação é uma matriz identidade). A adequabilidade dos dados foi avaliada utilizando o critério de Kaiser-Meyer-Olkim, que compara as correlações parciais e simples, assumindo valores entre 0 e 1 . 0 modelo estimado 
apresentou o valor de 0,614 , o que indica uma boa adequação da amostra à análise fatorial (HAIR et al., 1995).

O índice de degradação ambiental ${ }^{6}$ para a atividade agropecuária nos municípios mineiros foi calculado tomando os fatores estimados. As regiões do Triângulo Mineiro/Alto Paraníba, Oeste, Sul e Sudeste apresentaram os maiores níveis de degradação ambiental proveniente da agropecuária, enquanto que municípios das regiões Norte e Noroeste, por exemplo, apresentam menores valores (Figura 1). Esse comportamento para o IGD entre as regiões era esperado, uma vez que esse capta a degradação da atividade agropecuária, e, portanto, regiões de maior intensidade agropecuária tendem a apresentar maiores índices, assinalando a pressão da atividade agropecuária sobre o meio ambiente.

Apesar dos elevados valores de degradação para região sul do estado, essa apresenta maior percentual de utilização de práticas de conservação do solo como o plantio em nível, presente em no mínimo $60 \%$ dos estabelecimentos. Essa técnica é justificada pela geografia acidentada da referida região e é importante para contornar ou diminuir o potencial de degradação ambiental resultante da atividade agropecuária intensiva em tração mecânica e defensivos, que revolvem os solos, erosão e contaminação dos corpos de água pelos defensivos e fertilizantes.

Destaca-se também a conservação de encostas, onde a maior taxa de utilização deu-se na microrregião de Lavras, Sul de Minas, com 37\% dos estabelecimentos a utilizando. Entretanto, poucos estabelecimentos plantam em terraços, sendo que a microrregião de Lavras apresenta a maior taxa de utilização dessa prática (12\% dos estabelecimentos). Esta baixa utilização pode estar associada aos custos para a construção dos terraços, bem como a necessidade de informação e complexidade da construção em áreas de alta declividade (WADT, 2003).

\footnotetext{
${ }^{6}$ Os fatores estimados e o índice de degradação ambiental para os municípios foram omitidos do trabalho em razão de espaço, mas podem ser obtidos junto aos autores.
} 


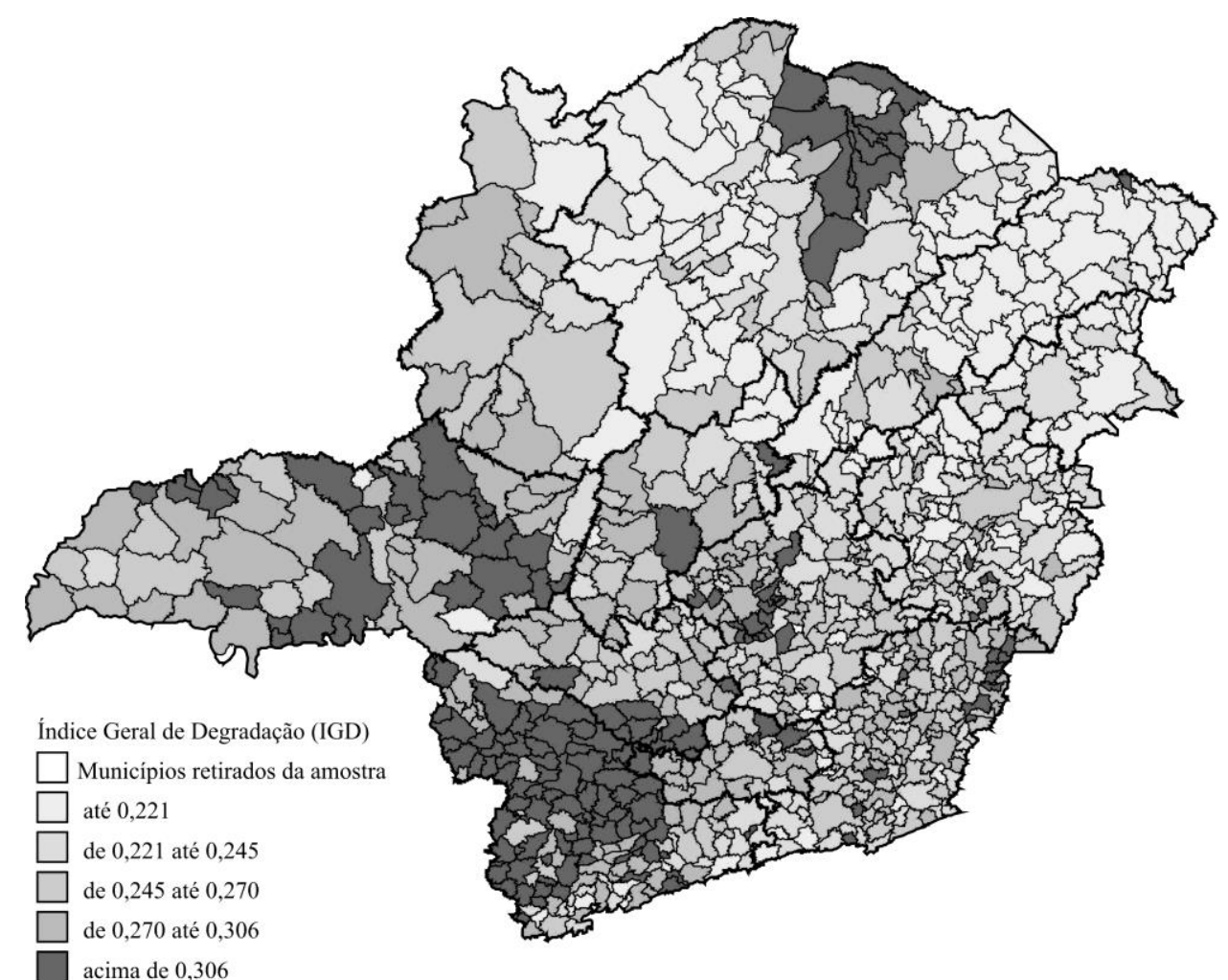

Figura 1. Índice de degradação ambiental dos municípios mineiros Fonte: Elaboração própria

As práticas de conservação do solo (terraçeamento e plantio em nível) possuem maior difusão nas regiões do Triângulo Mineiro/Alto Paraníba, nas microrregiões de Uberaba, Unaí, Frutal e Patrocínio, presentes em no mínimo $14 \%$ dos estabelecimentos agropecuários. Esse percentual de utilização pode estar associado à tecnologia (maior utilização de tratores por estabelecimento) e à informação dos produtores destas regiões. A utilização de práticas de rotação de culturas também é expressiva nessas regiões e também no Noroeste mineiro, enquanto a renovação de pastagens predomina nas regiões Norte, Centro e Campos das Vertentes. Destaca-se a baixa proporção da área coberta com matas em todas as regiões mineiras, inferior a $20 \%$, percentual mínimo ao exigido legalmente no estado. Esse pequeno percentual de áreas ocupadas com matas pode facilitar a erosão e carregamento da camada superficial do solo e assoreamento dos rios.

Apesar da maior ou menor utilização de práticas de conservação do solo e do meio ambiente, a proporção dos estabelecimentos que as utilizam, de forma geral, é baixa. Exceto para o plantio em nível, os demais cuidados ambientais são adotados por no máximo $40 \%$ dos estabelecimentos. Os elevados valores estimados para a degradação ambiental, tomando como base a intensidade da produção agropecuária, quando confrontados com o baixo percentual de produtores que adotam práticas de conservação indicam a importância de se atentar para ações que elevem a adoção dessas práticas, como estratégia de redução do potencial de degradação ambiental. Ademais, destaca-se que no longo prazo esse tipo de exploração pode não ser viável, podendo a produção agropecuária apresentar queda de produtividade, aumento dos custos pelo empobrecimento do solo, contaminação das águas, etc.

Revista de Estudos Sociais | Ano 2017, N. 38, V. 19, Pag. 59 
Assim sendo, a próxima seção analisa a relação de algumas características produtivas dos estabelecimentos agropecuários e práticas de controle da degradação com a degradação ambiental e seu potencial de redução/elevação da degradação.

\subsection{Regressão Quantílica}

A relação entre variáveis associadas à produção agropecuária, descritas anteriormente, e o Índice Geral de Degradação (IGD) para os municípios foi analisada utilizando a regressão quantílica na forma log-lin, estimada para os quantis 0,$10 ; 0,50$; e 0,90 (Tabela 4). Na estimação, maiores quantis estão associados a maior degradação e menores quantis, a menor degradação. A estimativa obtida por mínimos quadrados ordinários também foi apresentada como forma de comparação entre os resultados.

Tabela 4. Estimativas da regressão quantílica e mínimos quadrados ordinários para o $\ln (\mathrm{IGD})$

\begin{tabular}{|c|c|c|c|c|}
\hline Coeficiente/Quantis & $\mathrm{q} .10$ & $q .50$ & q.90 & MQO \\
\hline Intercepto & $-1.74^{\star \star \star}$ & $-1.53^{\star * *}$ & $-1.29^{\star \star \star}$ & $-1.5^{\star \star \star}$ \\
\hline Plantio & $0.39^{* * *}$ & $0.31^{* * *}$ & 0.12 & $0.33^{\star \star \star}$ \\
\hline Plantio2 & $-0.4^{\star * *}$ & $-0.29^{\star \star *}$ & -0.05 & $-0.33^{\star \star \star}$ \\
\hline Terraços & -0.07 & -0.18 & $-0.72^{\star \star \star}$ & -0.17 \\
\hline Terraços2 & 0.09 & 0.12 & $1.39^{\star \star \star}$ & 0.12 \\
\hline Rotação & 0.21 & $0.36^{\star \star *}$ & 0.26 & $0.30^{\star \star \star *}$ \\
\hline Rotação2 & -0.3 & $-0.55^{\star \star \star}$ & -0.35 & $-0.46^{* *}$ \\
\hline Renovação & $0.3^{* \star}$ & -0.04 & 0.26 & 0.04 \\
\hline Renovação2 & $-0.53^{\star *}$ & 0.07 & -0.04 & 0.02 \\
\hline Pousio & 0.05 & 0.01 & -0.22 & 0.04 \\
\hline Pousio2 & -0.12 & -0.04 & 0.18 & -0.14 \\
\hline Proteção & 0.06 & $0.06^{*}$ & 0.03 & 0.01 \\
\hline Matas & 0.12 & -0.08 & -0.13 & -0.08 \\
\hline Matas_2 & $-0.48^{\star \star \star}$ & $-0.39^{\star * *}$ & -0.14 & $-0.4^{\star \star \star}$ \\
\hline Milho & 0.02 & 0.01 & -0.01 & -0.01 \\
\hline Café & $0.78^{\star \star \star}$ & $0.73^{\star \star \star}$ & $0.58^{\star \star \star}$ & $0.74^{\star \star \star}$ \\
\hline Pastagens & $0.08^{\star *}$ & 0.02 & -0.02 & 0.02 \\
\hline Leite & $-8 E-4^{*}$ & $-1 E-3^{\star \star \star}$ & $-3 E-3^{\star \star \star}$ & $-1 E-3^{* * *}$ \\
\hline Suíno & $5 \mathrm{E}-4^{* * *}$ & $2 E-4^{\star * *}$ & $-6 E-5$ & $3 E-4^{\star *}$ \\
\hline Tratores & 0.06 & $0.1^{\star \star \star}$ & $0.33^{\star \star \star}$ & $0.15^{\star \star \star}$ \\
\hline Implementos & $0.1^{*}$ & $0.12^{\star \star *}$ & $0.07^{* *}$ & $0.1^{* \star *}$ \\
\hline
\end{tabular}

Número de observações 851

Fonte: Elaboração própria. Nota: ${ }^{* \star *}$ Significativo a 1\%; ${ }^{* \star}$ Significativo a 5\%; e * Significativo a $10 \%$.

As variáveis referentes ao plantio em nível, utilização de terraços, rotação de culturas, renovação de pastagens e áreas em pousio ou descanso foram estimadas na forma quadrática, haja vista que o aumento contínuo da área com essas práticas pode resultar na incorporação de áreas de matas e 
preservação permanente, por exemplo, o que contribuiria para a degradação ambiental. Tais variáveis na forma quadrática estão retratadas (Tabela 4) por "Plantio2", "Terraços2", "Rotação2", "Renovação2" e "Pousio2", respectivamente.

Inicialmente, era esperado que as variáveis "Plantio", "Terraços" "Rotação", "Renovação", "Pousio", "Proteção", "Matas" e "Matas_2" apresentassem sinais negativos e seus respectivos pares quadráticos exibissem sinais positivos, retratando que um aumento nessas inicialmente reduziria a degradação ambiental até um ponto mínimo e posteriormente a degradação aumentaria. Eram esperadas associações positivas entre a degradação ambiental e as variáveis "Milho", "Café", "Pastagens", "Leite", "Suínos", "Tratores" e "Implementos".

Para o plantio em nível as estimativas por mínimos quadrados ordinários indicam um efeito de 0,099 pontos percentuais, considerando o valor médio para essa variável. Assim, o aumento de um ponto percentual na área com plantio em nível eleva a degradação em $9,9 \%$ no ponto médio.

Vale ressaltar, entretanto, que o resultado ora apresentado pelo MQO não permite visualizar como esse efeito está distribuído. O questionamento acerca de se a utilização do plantio em nível, e das demais variáveis utilizadas na regressão, distribuem-se igualmente entre os estratos ou níveis de degradação ou se algum estrato se beneficia mais que os outros de práticas de conservação, por exemplo, pode ser visualizado por meio da regressão quantílica

Assim, o aumento na área plantada com café em um ponto percentual está relacionado ao aumento na degradação ambiental em até $78 \%$, para os produtores de menor IGD (quantil 0,10 ), sendo que essa relação reduz com 0 aumento da degradação para $58 \%$ (quantil 0,90 ).

Para as variáveis na forma quadrática observa-se a existência de um valor ótimo (Figura 2), e que algumas dessas variáveis apresentam relação significativa contrária à esperada, como "Plantio" e "Rotação, com coeficientes significativos e relacionados negativamente à degradação. Desta forma, o aumento na área com plantio em nível estaria associado, inicialmente, a um aumento da degradação ambiental. A degradação atingiria seu ápice quando $48,75 \%$ da área dos estabelecimentos agropecuários estiver sendo utilizada com o plantio em nível. Interessante notar que a relação entre o plantio em nível e o IGD não apresentaria um ponto ótimo, uma vez que há uma tendência de aumento do IGD com o aumento da área com plantio em nível para todos os valores dessa última variável, destacando, entretanto, que essa variável não foi significativa nesse quantil. 


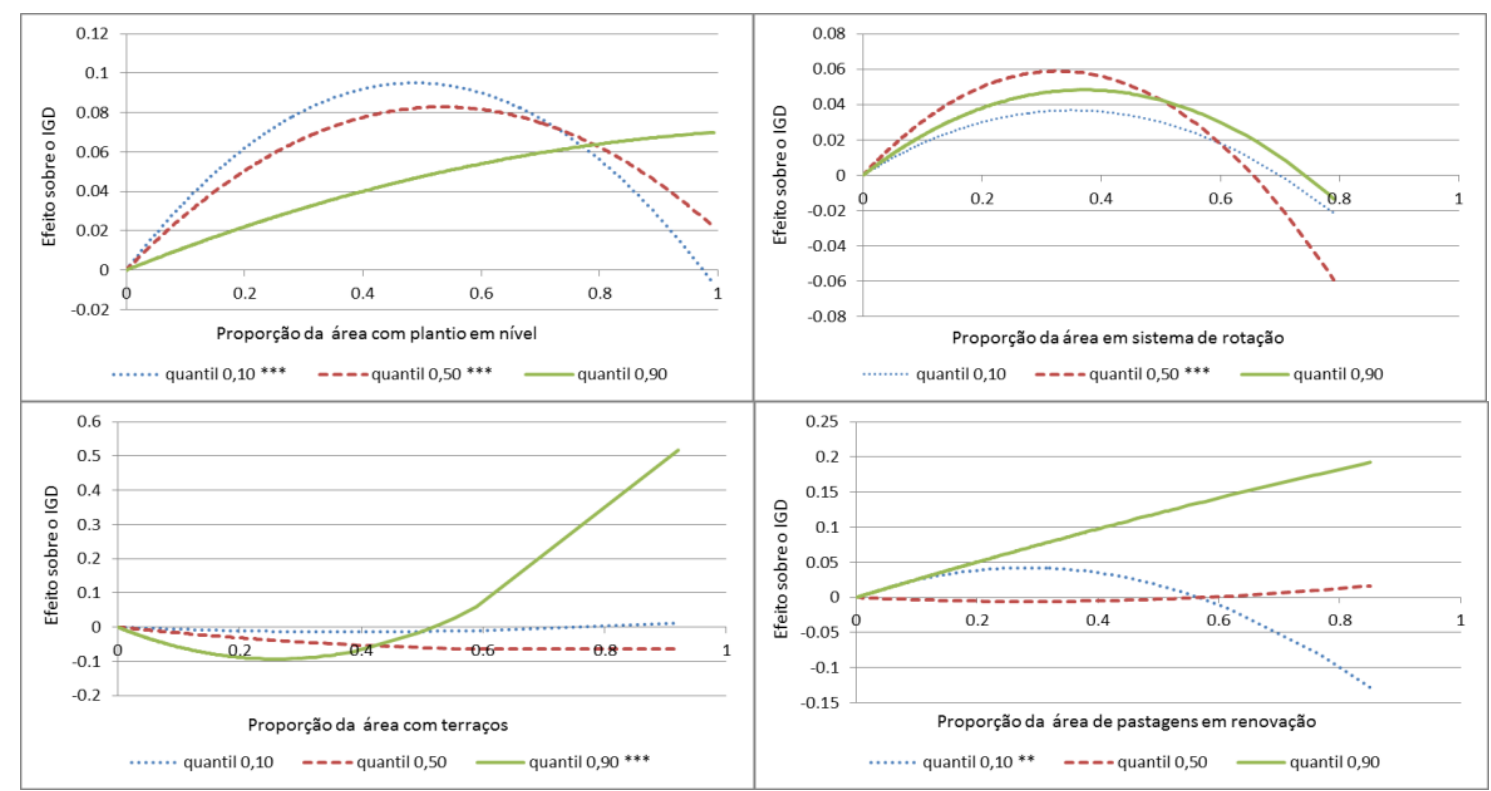

Figura 2. Efeito da utilização de rotação, plantio em nível, terraços e renovação de pastagens sobre a degradação.

Fonte: Elaboração própria. Nota: ${ }^{* *}$ indica que o parâmetro foi significativo a $1 \%{ }^{* *}$ indica que o parâmetro estimado foi significativo a $5 \%$.

As variáveis para utilização da rotação de culturas e renovação das pastagens apresentaram associação ao IGD semelhante àquela do plantio em nível (considerando os parâmetros significativos), em que a degradação atingiria o máximo quando a área ocupada com rotação de culturas ou renovação representasse, aproximadamente, $30 \%$ da propriedade, reduzindose, posteriormente, com aumentos proporcionais da área. A relação entre o IGD e a utilização do plantio em nível e rotação de culturas pode ser atribuída à forma como os produtores utilizam essas práticas de conservação, tratando-as como controle em detrimento de práticas preventivas. Assim, quando a degradação atinge um nível considerado elevado pelos produtores, esses são incentivados a adotar práticas de controle da degradação, praticas essas posteriores à degradação.

Já a variável utilização dos terraços (quantil 0,90) apresentou comportamento esperado, sendo que uma proporção de, aproximadamente, 0,25 da área ocupada com terraços apresentaria a maior redução do IGD (10\%). Posteriormente, o aumento da área ocupada com terraços elevaria o IGD. Ressalta-se, entretanto, como tratado anteriormente, que a proporção da área com terraços em Minas Gerais é baixa, apenas 5\% em média, sinalizando, desta forma, que na prática essa relação não seria observada.

A criação de suínos e a produção de leite, apesar de significativas, não apresentaram relação significante com a degradação agropecuária, ou seja, pelas estimativas, o aumento ou redução nessas não estaria associado à degradação. É também importante ressaltar a ausência de relação significativa entre a presença de matas na propriedade ("Proteção" e "Matas") e a redução da degradação ambiental proveniente da agropecuária. Entretanto, a área ocupada com matas destinadas à reserva legal (Matas_2), predominantemente, apresentou relação negativa e estatisticamente significativa à degradação ambiental. $\mathrm{O}$ aumento em 1 ponto percentual da área com matas e florestas naturais destinadas à preservação permanente foi

Revista de Estudos Sociais | Ano 2017, N. 38, V. 19, Pag. 62 
estimado como relacionado à redução do IGD em até $49 \%$, para os produtores de menor degradação (quantil 0,25).

A relação positiva entre o IGD e o número de tratores e o número de implementos era esperada e corrobora a hipótese de que o aumento na intensidade produtiva contribuiria para o aumento da degradação proveniente da agropecuária. $O$ maior número de tratores pode ser relacionado ao maior da mecanização agrícola da produção, resultando em maior compactação da camada inferior do solo e maior revolvimento da camada superficial, dificultando a infiltração da água nesse solo compactado, o que pode provocar erosão e empobrecimento dos solos e assoreamento dos corpos de água.

O aumento em uma unidade no número de tratores por estabelecimento está associado à elevação do IGD em 10\%, 9\% e 14\% para os quantis 0,25 , 0,50 e 0,75 , respectivamente. A elevação do IGD associada ao aumento no número de implementos agrícolas por estabelecimento (em uma unidade) foi estimada em $10 \%, 12 \%$ e $11 \%$ para os quantis $0,25,0,50$ e 0,75 , respectivamente. Esse resultado corrobora a relação encontrada entre Tratores e o IGD.

As estimativas (Tabela 4) exibem diferenças, em valor absoluto, na associação entre as variáveis explicativas e o IGD conforme a magnitude da degradação ambiental proveniente da agropecuária. Por exemplo, o aumento em um ponto percentual na variável "Matas_2" está associado ao aumento de $49 \%$ da degradação, para os produtores da calda inferior do IGD, enquanto que para os estabelecimentos de degradação mediana esse acréscimo seria de $35 \%$. Entretanto, essa diferença deve ser analisada estatisticamente. Assim, o teste de Wald para igualdade dos parâmetros entre os quantis foi estimado.

O teste de Wald indicou que apenas as variáveis "Leite" e "Suíno" estariam relacionadas diferentemente à degradação ambiental para os diversos quantis dessa variável (quantil 0,25, 0,50 e 0,75). O teste apresentou estatística calculada de $F_{2,2551}=10,10$ e $F_{2,2551=25,09}$, para essas variáveis, respectivamente, significativo em nível de significância de 1\%. As demais variáveis não apresentam relação diferenciada sobre maiores ou menores nível de degradação ambiental.

\section{Conclusões}

A estimativa do Índice Geral de Degradação ambiental dos municípios mineiros apresentou, de modo geral, maiores níveis naquelas regiões de maior intensidade na produção agropecuária e, ou acidentadas, como Sul e Sudeste de Minas Gerais e Triângulo Mineiro. Embora, em tais regiões, a utilização do plantio em nível está presente na maioria dos estabelecimentos agropecuários, como descrito anteriormente. As demais práticas de conservação apresentaram baixo nível de utilização pelos estabelecimentos. Destaca-se também a baixa proporção das áreas destinadas à reserva legal.

O IGD apresentou estimativas elevadas para grande parte dos municípios mineiros. Esta degradação pode ser resultado do baixo envolvimento dos produtores, interesse pela conservação do meio ambiente ou custos associados, dado a baixa proporção dos estabelecimentos que adotam práticas de conservação do meio ambiente. Este comportamento demonstra a necessidade de medidas de correção do padrão de produção agropecuária, 
bem como ações de difusão de práticas de conservação, permitindo a redução da degradação e, desta forma, conduzir a maiores produtividades.

O estudo permitiu avaliar a relação entre algumas atividades e práticas agropecuárias e a degradação ambiental. Destaca-se que as práticas de conservação do meio ambiente não estariam sendo utilizadas como ações preventivas de conservação, e sim como estratégia de controle posterior à degradação já existente, como a erosão do solo, por exemplo. Ademais, a maior intensidade da produção agropecuária, captada pelo uso de tratores e equipamentos apresentou contribuição importante para elevações da degradação ambiental pelo maior revolvimento e compactação do solo. Quanto ao cultivo do café, esse apresentou grande potencial de elevação da degradação, podendo ser associado notadamente ao uso de agrotóxicos. Essa é uma relação importante dada a importância do cultivo de café para o estado, principalmente quando se considera a área ocupada.

O estudo demostra a necessidade da ação dos órgãos de assistência técnica e demais agentes do setor agropecuário na conscientização do produtor quanto à importância da utilização das boas práticas agrícolas como estratégia de prevenção da degradação, haja vista que a adoção dessas, como controle, acarreta em maiores custos econômicos e ambientais. Ademais, é necessário o uso racional de máquinas e equipamentos agrícolas, de forma a evitar a compactação, o revolvimento excessivo do solo e a consequente erosão.

Uma limitação na estimação da degradação ambiental da atividade agropecuária refere-se ao nível de agregação dos dados, que não permitiram a estimação de tal medida para cada produtor e por atividade produtiva, o que seria relevante. Entretanto, os resultados obtidos fornecem uma proxy satisfatória da degradação proveniente da agropecuária, permitindo concluir que o padrão de produção agropecuária deteriora os recursos naturais e aponta, ainda, a necessidade de ações de redução dessa degradação, para a manutenção da produtividade e competitividade no longo prazo.

\section{Referências}

BARRODALE, I.; ROBERTS, F. D. K. Solution of an overdetermined system of equations in the $\mathrm{l}_{1}$ norm. Communications of the Association for Computing Machinery, v.17, n. 6, p. 319-320, 1974.

BARROS, G.S.C. et al. PIB do Agronegócio: estado de Minas Gerais. 32 p. CEPEA, 2017. Disponível em: < http://www.cepea.esalq.usp.br/upload/kceditor/files/Relatorio\%20PIBAGRO\%20 Minas\%20Gerais janeiro(1).pdf>. Acesso em 16 abril. 2017.

CAMERON, A.C; TRIVEDI,P.K. Microeconometrics Using Stata. Stata Press, 2009, $692 \mathrm{p}$.

CARVALHO, L.M.T. et al. Qualidade ambiental, risco ambiental e prioridades para conservação e recuperação. In: SCOLFORO, J.R.S.; OLIVEIRA, A.D.; CARVALHO, L.M.T. Zoneamento Ecológico Econômico do Estado de Minas Gerais - Vulnerabilidade Natural. Lavras, UFLA, p. 21-45, 2008. 
CUNHA, N.R.S. et al A intensidade da exploração agropecuária como indicador da degradação ambiental na região dos Cerrados, Brasil. Revista de

Economia e Sociologia Rural, Rio de Janeiro, v. 46, n. 02, p. 291-323, 2008.

DI, H.J.; CAMERON, K.C. Calculating nitrogen leaching losses and critical nitrogen application rates in dairy pasture systems using a semi-empirical model. New Zealand Journal of Agricultural Research, v. 43, n.1, p. 139 147, 2000.

DI, H.J.; CAMERON, K.C. Nitrate leaching in temperate agroecosystems: sources, factors and mitigating strategies. Nutrient Cycling in

Agroecosystems, v. 46, n. 3, p. 237-256, 2002.

ENGSTRÖM, R. et. al. Environmental assessment of Swedish agriculture. Ecological Economics, v. 60, n. 3, p. 550 - 563, 2007.

EL KHASLILI, L.H.P. et al. ABC da agricultura familiar - preservação e uso da Caatinga. Brasília: Embrapa Informação Tecnológica; Embrapa Semi Árido. 2007, p. 39.

FERNANDES, E.A.; CUNHA, N.R.S.; SILVA, R.G. Degradação ambiental no estado de Minas Gerais: indicadores e índices. Revista de Economia e Sociologia Rural. v. 43, n. 1, p. 179 - 199, 2005.

KOENKER, R.; BASSETT JÚNIOR, G. Regression Quantile. Econometrica, v. 46, n. 1, p. 33-50, 1978.

KOENKER, R.W.; D'OREY Computing regression quantiles. Applied Statistics, v. 36, n. 3, p. 383 -393, 1987.

HAO, L.; NAIMAN, D.Q. Quantile Regression. Sage Publications, Inc., 2007. $125 p$.

HAIR, J.F. et al. Multivariate data analysis: with readings. New Jersey:

Prentice Hall, 1995. 768p.

HÄRDLE, W.; SIMAR, L. Applied multivariate statistical analysis. Berlin: Springer, 2003. $478 \mathrm{p}$.

LEMOS, J. J. S. Indicadores de degradação no Nordeste Sub-úmido e Semiárido. In: CONGRESSO BRASILEIRO DE ECONOMIA E SOCIOLOGIA RURAL, 34, 2001, Brasília, DF. Anais... Brasília, DF: SOBER, 2001. p.1-10.

LOPÉZ, R. Environmental externalities in traditional agriculture and the impact of trade liberalization: the case of Ghana. Journal of Development

Economics, v. 53, n.1, p.17-39, 1997.

MINGOTI, S.A. Análise de dados através de métodos de estatística multivariada - Uma abordagem multivariada. Belo Horizonte: Editora UFMG, 2007. 295p.

MALLMANN, S.M. et al. Efeitos da água residuária da suinocultura na biodegradação de lodo têxtil codisposto com capim Napier. In: Simpósio Internacional sobre Gerenciamento de Resíduos de Animais Tratamento de Dejetos de Animais, I, 2009, Florianópolis. Anais... SIGERA, 2009. 
MAROUELLI, R.P. O desenvolvimento sustentável da agricultura no cerrado brasileiro. 64f. 2003. Monografia (Gestão Sustentável da Agricultura Irrigada). Fundação Getúlio Vargas, Brasília.

PALHARES, J,C,P. Licenciamento ambiental e produção de aves de corte e postura. Produção Animal: Avicultura. v.6, n. 1, p.10-11, 2007.

RACHWAL MFG; DEDECEK RA. Influência da aeração e da disponibilidade hídrica em cambissolos e latossolos com diferentes níveis de erosão sobre a produtividade e a qualidade da cultura da batata. Revista Brasileira de Ciência do Solo. v. 20, n. 1, p. 485-491, 1996.

RODRIGUES, W. Valoração econômica dos impactos ambientais de tecnologias de plantio em região de Cerrados. Revista de Economia e Sociologia Rural, v. 43, n. 1, p. 135-153, 2005.

SIDRA-IBGE- SISTEMA IBGE DE RECUPARAÇÃO AUTOMÁTICA INSTITUTO BRASILEIRO DE GEOGRAFIA E ESTATÍSTICA. Censo Agropecuário 2006. Disponível em:

$<$ http://www.sidra.ibge.gov.br/bda/pesquisas/ca/default.asp?z=p\&o=2>. Acesso em 20 nov. 2012.

SILVA, R.G.; RIBEIRO, C.G. Análise da degradação ambiental na Amazônia Ocidental: um estudo de caso dos municípios do Acre. Revista de Economia e Sociologia Rural. v. 1, n. 42, p. 81-110, 2004.

SINGH, R.B. Environmental consequences of agricultural development: a case study from the green revolution state of Haryana, India. Agriculture, Ecosystems and Environment, v. 1-3, n. 82, p. 97-103, 2000.

SOARES, W.L; FREITAS, E.A.V.; COUTINHO, J.A.G. Trabalho rural e saúde: intoxicação por agrotóxicos no município de Teresópolis - RJ. Revista de Economia e Sociologia Rural, v. 43, n. 4, p.685-701, 2005.

VIANA, J.H.M. el al. Manejo do Solo para a Cultura do Milho. Circular Técnica, n. 77. Sete Lagoas: Embrapa, 2006. 14p.

WADT, P.G.S. Construção de terraços para controle da erosão pluvial no estado do Acre. Rio Branco: Embrapa Acre, 2003, 43p. (Documento 85).

WATSON, K. Deforestation, coffee cultivation, and land degradation: the challenge of developing a sustainable land management strategy in Brazil's Mata Atlântica rainforest. 2005. 39 f. Tese (Environmental Science) Lund University, Suécia.

ZILBERMAN, D. et. al. Agriculture and the environment: an economic perspective with implications for nutrition. Food Policy, v. 24, n. 2-3, p. 211229, 1999. 